School of Finance

\title{
University of St.Gallen
}

BANKS' LOAN SCREENING INCENTIVES WITH CREDIT RISK TRANSFER: AN ALTERNATIVE TO RISK RETENTION

MARC ARNOLD

Working PAPERS ON FinANCE No. 2014/2

SWISS INSTITUTE OF BANKING AND FINANCE (S/BF - HSG)

FEBRUARY 2014 


\title{
Banks' Loan Screening Incentives with Credit Risk Transfer:
}

\section{An Alternative to Risk Retention}

\author{
Marc Arnold *
}

February 11, 2014

\begin{abstract}
This article analyzes the impact of credit risk transfer on banks' screening incentives on the primary loan market. While credit derivatives allow banks to transfer risk to investors, they negatively affect the incentive to screen due to the asymmetry of information between banks and investors. I show that screening incentives can be reestablished with standardized credit derivatives that fully transfer the underlying loan default risk. In particular, a callable credit default swap reveals a loan's quality to the investor by letting him observe the bank's readiness to pay for the implicit call feature. The ability to signal loan quality induces screening incentives. The paper also examines the impact of current developments such as higher regulatory capital standards, stricter margin requirements, and central clearing on the design of the optimal credit risk transfer contract.
\end{abstract}

JEL Classification Codes: G18, G28

Keywords: Credit Risk Transfer, Callable Credit Default Swaps, Screening Incentives

\footnotetext{
* Office address: Rosenbergstrasse 52, CH-9000 St. Gallen, Switzerland, Phone: 0041-71-224-7076, Email: marc.arnold@unisg.ch. Marc Arnold is an assistant professor of Finance at the Swiss Institute of Banking and Finance at the University of St. Gallen. This research was supported by the Swiss Finance Institute, the NCCR FINRISK and the University Research Priority Program "Finance and Financial Markets", a research instrument of the University of Zürich. I'm grateful for the support of Alexander Wagner, as well as the very helpful comments from Darrell Duffie, Anke Gerber, Olivier Scaillet, Philipp Schonbucher, Ramona Westermann and seminar participants at the University of Zurich.
} 


\section{Introduction}

The credit derivatives market segment has been one of the most innovative and fastestgrowing before the breakout of the recent subprime mortgage crisis. Barrett and Ewan (2006) estimated a market size of USD 5 trillion for 2004. Two years later, the outstanding notional already amounted to USD 20 trillion, exceeding the US GDP of USD 13 trillion in 2006. Academics and practitioners argue that two problems associated with credit risk transfer are among the main causes of the crisis. First, credit risk transfer weakens banks' lending discipline on the primary loan market (see, e.g., Berndt and Gupta, 2009; Purnanandam, 2011), which can seriously undermine the resilience of a banking system. Second, a theoretical benefit of credit derivatives is that by transferring credit risk from lenders to investors, the risks should be spread throughout the economy with minimal systemic effect. According to Acharya et al. (2009), however, banks retained themselves a significant portion of the credit risk they originated before the crisis. In fact, they got caught holding up to 300 billion of leveraged loans when the market collapsed in late July 2007. If credit risk had been fully transferred, banks and other financial intermediaries would not have suffered the huge losses. The dramatic decrease in the activity on the structured credit derivative markets in 2008 , and the enormous impact of the crisis on the economy painfully reveal the importance to address these problems.

This paper proposes a simple credit derivative structure that can solve the lending discipline problem without requiring default risk retention by the loan originating bank. I start by illustrating how credit risk transfer adversely affects the incentives of a bank to screen a loan. Subsequently, I suggest to transfer the credit risk of a loan by using a callable credit default swap (CCDS) that consists of a credit default swap $(\mathrm{CDS})^{1}$ combined with a plain vanilla put option on the CDS. In principle, the CCDS corresponds to a CDS that can be canceled at a predetermined date by the protection buyer. The basic idea is that by using a CCDS, the bank can signal the quality of the underlying loan through its readiness to pay

\footnotetext{
${ }^{1} \mathrm{~A}$ credit default swap is a specific kind of counterparty agreement that allows the transfer of third party credit risk from one party to the other. For example, one party in the contract could be a lender facing credit risk from a third party borrower, and the counterparty in the credit default swap agrees to insure this risk in exchange of regular periodic fee payments.
} 
for the implicit call feature, which restores the incentive to screen.

The presented signaling mechanism features two main advantages. First, academics and practitioners call for stricter regulation of credit risk transfer as a consequence of the recent crisis. Among the most prominent suggestion is the implementation of a centrally cleared market for credit risk, one of the central planks of the Dodd-Frank reform. While central clearing is argued to reduce the consequences of market opacity (see, e.g., Acharya and Bisin, 2014), it entails standardization. The reason is that because of the costs of setting up, analyzing, and pricing each type of derivative, or due to the contingency of a sudden need to unwind positions held with a defaulted clearing member, central counterparties will only clear frequently traded, standardized credit derivatives (Duffie et al., 2010; Bliss and Steigerwald, 2006). One advantage of credit risk transfer on the uncleared OTC market, however, is that banks can trade tailored credit derivative contracts that are flexibly customized to signal the quality of the underlying loan (see, e.g., Nicolò and Pelizzon, 2008). Such signaling contracts can mitigate the information asymmetry among market participants that is, according to Duffee and Zhou (2001), the main reason for the lending discipline problem. As individually tailored credit derivatives are not liquid enough to be centrally cleared (Duffie et al., 2010), the current transition from uncleared OTC to centrally cleared markets calls for signaling mechanisms to address the lending discipline problem that can be implemented with centrally clearable, standardized credit derivatives. CDSs are already centrally cleared. In contrast to the declines in trading volumes across credit derivative instruments over the recent years, the plain vanilla credit option volume has recently picked up dramatically. Market participants estimate a doubling of notional for every six-month period (Pengelly, 2010). In fact, the notional amount outstanding of OTC credit derivative options has increased by $400 \%$ between 2010 and 2013 (BIS, 2013). The ECB (2009) suggests that CDS options could benefit from increased investor interest in the environment of a migration to central clearing. Due to the raising liquidity of options on CDSs, CCDSs that simply consist of a CDS and a plain vanilla option should soon become centrally clearable.

Second, as the right to call the hedging contract is at the discretion of the bank, a CCDS fully transfers the default risk of the underlying loan. Hence, the contract induces prudent 
bank behavior on the primary loan market without simultaneously requiring loan default risk retention. This complete risk transfer coincides with the whole point of credit derivatives to spread the credit risk that is concentrated with the originators throughout the economy with minimal systemic effect (Acharya et al., 2009).

The basic situation I study is the following. Consider three market participants, a bank (B), an investor (S), and a borrowing firm (F). Their relationship is sketched in Figure 1. Suppose that the loan-originating B is subject to credit risk constraints, either by an internal limit on concentrated lending or by capital adequacy requirements. Thus, B needs to transfer the credit risk of a new loan to $\mathrm{S}$ via credit default swap. S demands a protection fee to compensate the expected default costs of the loan. The problem of standard credit risk transfer techniques is that they reduce B's incentive to screen a new loan because S, not B, now bears the consequences of adverse loan quality. This misbehavior is anticipated by $\mathrm{S}$, and, hence, reflected in a larger protection fee. B consequently faces information asymmetry costs when transferring credit risk. Additionally, if the protection fee turns out to be above the loan rate earned, the market breaks down as in Akerlof (1970), and an otherwise profitable loan cannot be granted (underinvestment). I argue that CCDSs restore screen-

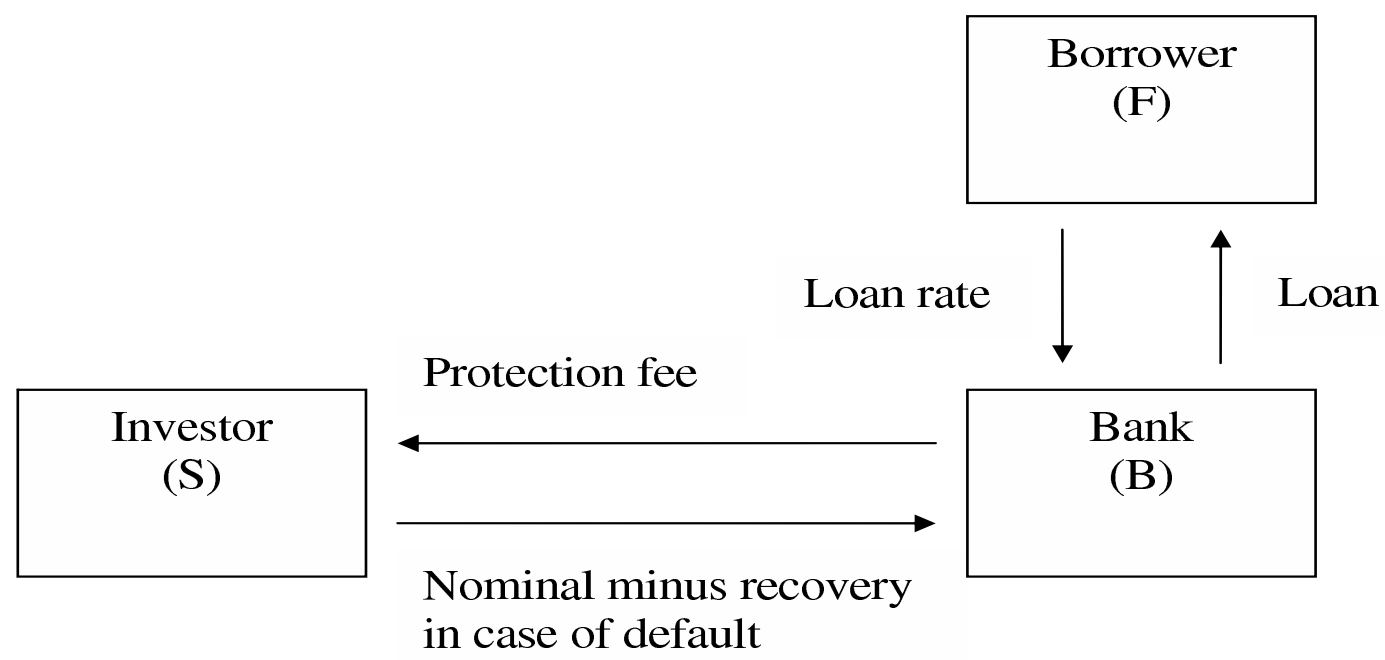

Figure 1: Market Participants. This figure depicts the market participants and their interactions in the model. 
ing incentives, thereby lowering the fair protection fee and preventing a market breakdown. Following Duffee and Zhou (2001), B's informational advantage is assumed to be relatively small for short-term payoffs, but relatively large concerning the payoffs far in the future. In this situation, consider using a callable CDS contract to transfer the credit risk to S. Once the date is reached upon which the Bank decides whether to call the contract, it does not have an informational advantage any more because only short-term payoffs remain up to maturity. Hence, the informed B's readiness to pay for the implicit call feature constitutes a credible signal of the loan's quality ex ante. The signal, therefore, allows the bank to express screening effort. Hence, B has an incentive to screen to lower the protection fee. It thereby reduces information asymmetry costs, while still achieving the primary objective of the credit derivative transaction, namely complete default risk transfer that admits diversification and optimization of regulatory capital.

I also discuss the optimal design of credit derivative contracts by comparing the proposed solution to partial protection approaches described in the literature. It turns out that the optimal security design depends on regulatory capital requirements. While designed to sustain stability in the financial system, these requirements in fact often impede credible partial protection solutions. As a consequence, callable credit default swaps evolve as the optimal signaling contract in many regulatory scenarios.

The article is based on the broadly discussed idea of banks having a unique ability to build relationships with their borrowers, thus simplifying monitoring (Diamond (1984)), long-term commitment (Von Thadden (1995)), and screening. There is a substantial debate among academics and practitioners about the impact of credit derivatives on the bank-borrower relationship due to a change in bank behavior. Concerns about credit derivatives undermining positive relationship-rents by causing misbehavior are expressed in several papers. Morrison (2005) argues that credit derivatives could adversely affect banks by reducing their incentive to screen and monitor borrowers. Hence, the use of credit derivatives may render bank loans less valuable because the loans would entail less of a certification effect. Arnold (2014) shows that central clearing of credit derivatives reduces the banks' lending discipline if credit risk transfer markets are not appropriately regulated. Empirical evidence that credit risk transfer 
adversely affects the lending behavior is found in Ashcraft and Sanots (2009), Keys et al. (2010), and Purnanandam (2011). The current article adds to this debate by showing that properly structured credit risk transfer does not necessarily erode the rents generated in the bank-borrower relationship.

My model is closely related to the literature on the application of strategic contracting within financial intermediation to mitigate information asymmetry problems (Gale and Hellwig, 1985; Innes, 1990; Von Thadden, 1995). For credit markets, the lemons problem and the ability to sell loans if banks have private information are discussed in Carlstrom and Samolyk (1995). In their setting, buyers realize that banks are selling loans due to capital constraints. Hence, the former acquire exposures even when they cannot perfectly screen the ex ante quality of loans, whereby the standard lemons problem can be avoided. The classical reference to loan sales and information asymmetry is the paper of Gorton and Pennacchi (1995). They conclude that if a bank can implicitly commit to holding a certain fraction of a loan, i.e., to provide limited recourse, the moral hazard associated with the loan sales market is reduced. Similar ideas are subsequently applied to articles on credit derivatives structured to mitigate information asymmetry problems. The first paper that rigorously considers the implications of credit derivatives for banks' risk-sharing is Duffee and Zhou (2001). The authors show how banks hedging high-quality loans can use credit derivatives with a maturity mismatch $^{2}$ to shift the risk of early default to outsiders. By retaining the risk of late default they avoid the lemons problem. Boot et al. (1993) provide the basic idea of splitting a risky cash flow into a senior and a subordinated security: The senior security is considered to be information-insensitive and can be sold to uninformed investors while the subordinated security is information-sensitive and, hence, tailored to informed investors. Riddiough (1997) extends this reasoning by arguing that loan bundling admits pool diversification, which softens information asymmetry. DeMarzo and Duffie (1999) show that pooling and shearing of loans allows the protection buyer to concentrate the "lemon's premium" in the first-loss block. Retention of this information sensitive block reduces the total lemon's premium by aligning the interests of the protection buyer with those of the protection seller. A variety

\footnotetext{
${ }^{2}$ In a maturity mismatch, the maturity of the credit derivative contract does not match the underlying loan contract.
} 
of papers follows the same idea. Franke et al. (2007), for example, model the optimal design of Collateralized Debt Obligations (CDOs). According to Nicolò and Pelizzon (2008), binary credit default basket contracts can be designed to signal the ability of banks to screen their borrowers.

My work distinguishes in two important ways from the literature that suggests to structure credit risk transfer contracts to mitigate information asymmetry problems. First, I show that signaling does not require complex OTC contracts, but can also be achieved with standardized contracts that qualify for central clearing. Second, the approaches discussed in the literature concentrate on signaling the bank's type by varying the quantity of insurance. This solution is a standard result within the insurance theory. ${ }^{3}$ As the recent subprime crisis has shown, however, retained risk constituted a major problems for banks. Hence, it is crucial to find ways through which banks can signal loan quality while completely transferring the associated loan default risk from their balance sheets. Moreover, market opacity can prevent banks from credibly committing to retain part of a loan's risk: A bank can transfer the remaining risk silently without informing either party. In fact, the current regulatory treatment in the Basel II and III jurisdictions may even encourage banks to do so in order to avoid the regulatory costs incurred with partially retained credit risk. An investor, consequently, does not know whether a bank truly retains some risk exposure and, hence, has an incentive to screen a loan. ${ }^{4}$ I argue that, in contrast to partial retention contracts, CCDSs provide a credible signal even if credit derivative trades are private in line with current market practice. As CCDS fully transfer the credit risk of a loan, there are no regulatory retention costs and, hence, no regulatory incentives to silently sell the implicit call feature.

The structure and the price of the credit derivative are the only information required to signal quality to the investor. The signal does not rely on generally unavailable information such as whether the lending constraint is binding, the reason why a bank is selling credit risk (Carlstrom and Samolyk, 1995), or hard-to-judge reputation effects (Gorton and Pennacchi, 1995). Finally, the choice of a premium as a signal yields an additional striking feature:

\footnotetext{
" Good" banks signal their quality by buying less insurance. "Bad" banks prefer to buy full insurance and to reveal their type.

${ }^{4}$ In line with this argument, there was a very active market for first-to-default basket contracts before the current crises that allowed banks to easily sell retained first loss pieces.
} 
Standard signaling models often use a wasteful signal. ${ }^{5}$ In contrast, the signaling premium provided in this paper accrues to the investor, an argument enhancing the marketability and liquidity of credit risk. I also show that the proposed signaling-mechanism is more attractive the stricter the regulatory capital requirements, and the more severe the information asymmetry problem.

For tractability, my model simply addresses two types of loans and two periods. Increasing the number of types to a continuum, or varying the length of the two subperiods does not change the basic insights as long as the structure of the information asymmetry is maintained.

The paper is organized as follows: The next section introduces the structure of the model. Section 3 discusses adverse selection, i.e., the screening problem, and derives the optimal credit derivative contract. Section 4 concludes. All valuation techniques and proofs are relegated to the Appendix A and B, respectively.

\section{A simple model of adverse selection}

\subsection{Structure of the model}

The model framework is adapted from Nicolò and Pelizzon (2008) to incorporate screening.

Consider a risk-neutral bank $\mathrm{B}$ providing a borrower $\mathrm{F}$ with a loan of nominal one. $\mathrm{B}$ charges a loan interest rate $\mathrm{i}$ to $\mathrm{F}$. As $\mathrm{B}$ is operating in a specialized loan market and maintains a close relationship to $\mathrm{F}$, its costs $\mathrm{C}$ to screen the borrower are relatively low. Screening reveals private information to B about the loan quality that can either be high or low. In case of a loan default, the bank only recovers the recovery rate $\mathrm{R}$ of the nominal of the loan.

Because internal or external constraints on loan default risk are binding, B seeks to completely transfer this risk to an investor S. The corresponding credit spread to be paid to transfer the risk with a CDS is denoted s. In case of a loan default during the life of the

\footnotetext{
${ }^{5}$ In Spence (1973), education is a wasteful signal. Risk retention in Franke and Krahnen (2005), and Duffee and Zhou (2001) is wasteful due to additional regulatory capital costs.
} 
CDS, $\mathrm{S}$ has to pay an amount 1-R to the bank in which $\mathrm{R}$ is the recovery rate of the loan. Financial markets are assumed to be competitive, and the risk-free interest rate is zero.

B's problem is to maximize the expected profit from the loan and the corresponding credit derivative. To transfer the credit risk of the borrower's loan to S, B selects between a credit default swap (CDS) and a callable credit default swap (CCDS). The structures do not differ with respect to the convention that $\mathrm{S}$ covers the loss of the reference credit's face value following a credit event ${ }^{6}$ in exchange for a protection fee. A (European) CCDS, however, gives $\mathrm{B}$ the additional right but not the obligation to call (unwind) the contract at a predefined point in the future. The CCDS structure can be split into its generic components, namely a CDS and a plain vanilla put option on the CDS with corresponding strike and exercise date. On credit risk markets, such a put option is usually called "receiver default swaption" (RS). ${ }^{7}$

There are three dates in the model outlined in Figure 2. $T_{0}$ is the starting date, $T_{1}$ the call date of the CCDS, and $T_{2}$ the maturity date of the loan. At $T_{0}, \mathrm{~B}$ decides whether to

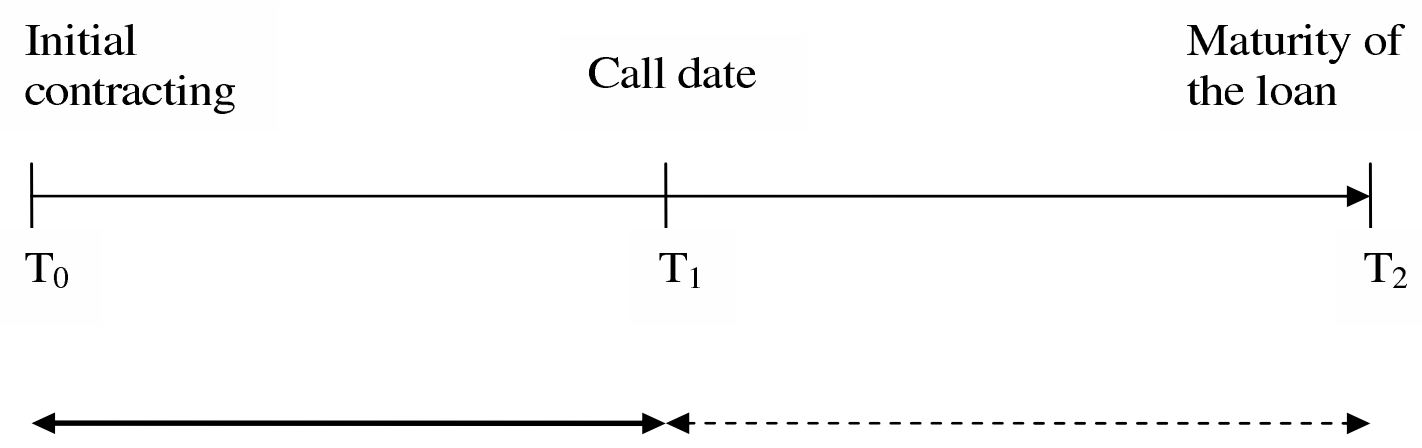

\section{Parties agree at $\mathrm{T}_{0}$ on the recovery rate from $T_{0}$ to $T_{1}$ \\ Information-asymmetry at $\mathrm{T}_{0}$ concerning the recovery rate from $\mathrm{T}_{1}$ to $\mathrm{T}_{2}$}

Figure 2: Time Structure. This figure illustrates the dates considered in the model.

screen a loan applicant. If it screens, $\mathrm{B}$ offers a CDS or a CCDS to $\mathrm{S}$ based on its private information. Without screening, this offer is based on public information. As soon as S signs

\footnotetext{
${ }^{6} \mathrm{~A}$ credit event is a legally defined event that typically includes bankruptcy, failure to pay and restructuring. Note that the correlation between a credit event of B and $\mathrm{S}$ is assumed to be zero.

${ }^{7}$ In a receiver default swaption, the option buyer pays a premium to the option seller for the right, but not the obligation, to sell CDS protection on a reference entity at a predetermined rate (strike) on a future date. See O'Kane et al. (2003), page 26.
} 
the credit derivative contract, the bank grants the loan. I only consider one call date at $T_{1}$. In a CDS, the protection fee payable by B to $\mathrm{S}$ is fixed during the contract's lifetime from $T_{0}$ to $T_{2}$. Transferring the credit risk of a loan via CCDS includes an option for B to call the protection at time $T_{1}$. I assume that given its loan risk constraint, the bank needs to hedge the loan with a CDS after a call. It is, consequently, only worthwhile for B to call if it can buy new protection at $T_{1}$ up to $T_{2}$ for a lower fee than the one initially agreed. In practice, there could be situations in which banks may not find a replacement protection at time $T_{1}$. Note, however, that they can simply avoid to call the CCDS in this case to remain fully default protected until $T_{2}$.

The information structure of the model deserves a closer description. I distinguish between freely available public information and costly private information. The former contains loan pricing parameters for the next time interval. To determine the fair CDS rate at $T_{0}$ for protection up to maturity, however, one does not only need the parameters from $T_{0}$ to $T_{1}$, but also the ones from $T_{1}$ to $T_{2}$. The latter piece of information corresponds to the private information. To illustrate the calculations, I consider the recovery rate $\mathrm{R}$ over $T_{1}$ to $T_{2}$ as the private information. ${ }^{8}$ The analysis can be applied analogously to alternative parameters such as the probability of default. Loans with a high $\mathrm{R}$ from $T_{1}$ to $T_{2}$ (high loans) yield a fair CDS rate $s^{H}$, and loans with a low recovery rate (low loans) have a fair CDS rate $s^{L}$. These fair CDS rates compensate an investor for the credit risk of a loan. Consistent with market practice, the investor is unable to observe a bank's credit derivative contract offers to other third parties, the bank's lending constraints, and the screening activities.

Figure 2 shows how the structure of the asymmetric information varies over the life of the loan. The information asymmetry at $T_{0}$ between $\mathrm{S}$ and a bank with private information refers to the recovery rate over the future time interval from $T_{1}$ to $T_{2}$. The key observation to mitigate adverse selection is the following: $\mathrm{B}$ and $\mathrm{S}$ realize at $T_{0}$ that, once they reach time $T_{1}$, there will be no more information asymmetry, since the recovery rate for the proximate period is public information.

Lacking private information, S observes B's choice of the hedging strategy, and eventually

\footnotetext{
${ }^{8}$ The recovery rate is the remaining value of a loan at default.
} 
updates beliefs concerning the future recovery rate of a loan. Let $\mu$ denote the probability of a high loan if beliefs are based on public information. $\rho$ indicates the assessed probability of a high loan if beliefs are updated after observing the bank's contract offer. The spreads $s(\mu)$ and $s(\rho)$, respectively, denote the expected CDS rates based on the corresponding beliefs. They represent the fair protection fee demanded by S for bearing a loan's credit risk.

The bank's payoff from using CDSs is as follows:

$$
\operatorname{Max}\left[0, V_{0,2}^{f e e}(i-s(\mu))\right]
$$

The bank obtains the interest i from granting the loan, and needs to pay $s(\mu)$ to hedge it. The protection fee $s(\mu)$ payable to $\mathrm{S}$ is fixed at time $T_{0}$ up to $T_{2}$. It is based on the public information $\mu$, as the bank has no mean to signal private information to the investor through a CDS. $V_{0,2}^{f e e}$ is the present value at $T_{0}$ of receiving one basis point up to $T_{2}$ as long as there is no default. Details on pricing can be found in the Appendix A. B grants and hedges a loan if the corresponding expected profit is positive $\left(V_{0,2}^{f e e}(i-s(\mu)) \geq 0\right)$. The bank can also reject the loan which results in a present value of zero.

In contrast to CDSs, CCDSs allow the bank to exploit the time varying structure of the information asymmetry. Consider the optimization problem of a bank that has detected a high recovery credit. The profit of the bank corresponds to

$$
\max _{P}\left[V_{0,2}^{f e e}(i-s(\rho))-P+A^{H}-C\right]
$$

$\mathrm{B}$ earns the rate $i$ from the loan and pays a protection fee $s(\rho)$ to $\mathrm{S}$ for the hedge. $\mathrm{P}$ denotes the premium paid for the right to call the contract. The economic value of this right is known to $\mathrm{B}$ after screening and corresponds to $A^{H}$ for a high, and $A^{L}$ for a low loan. It depends (besides publicly known parameters) on the recovery rate $\mathrm{R}$ from $T_{1}$ to $T_{2}$, i.e., on the private information. $\mathrm{B}$ and $\mathrm{S}$ know at $T_{0}$ that the contract is eventually called at $T_{1}$. As there will be no more information asymmetry at this date, the value of the call feature to $B$ does not depend on the private information. Hence, a bank is able to signal the loan's type by expressing its readiness to pay for the right to call at $T_{0}$. In particular, after detecting a 
high loan, it simply offers a larger $\mathrm{P}$ than the premium a bank with a low recovery credit - or a bank that has not screened - is ready to pay. As a consequence, only high loans are hedged with CCDSs. S, in turn, updates beliefs to $\rho=1$ which induces $s(\rho)=s^{H}$. The readiness to pay for the implicit call feature at time $T_{0}$ signals the future recovery rate, and, therefore, dissolves the information asymmetry between the bank and the investor.

In the signaling game between $\mathrm{B}$ and $\mathrm{S}$, the latter is not perfectly informed about the loan parameters. Therefore, I follow Osborne (2004) and use the model of a strategic, Bayesian two-player game with imperfect information. A pure strategy equilibrium is defined as a duple of actions, one for the investor S and one for the bank B. The actions of each player are the following: B can choose to grant and hedge a loan without screening, to stay out of the market if the expected profit is negative, or to screen and select the appropriate instrument to transfer the risk of the exposure, i.e., a CDS or a CCDS. The payoff to each player depends on the other player's action and on the market environment. In an equilibrium of the Bayesian game, the action chosen by each player is optimal, given the action chosen by the other player. An equilibrium is explicitly defined with respect to the perceived probabilities of high and low loans.

\subsection{Discussion of the assumptions}

The model assumes that S cannot infer the credit's type by looking at the loan rate. This assumption is supported by the observations that (i) B may not have an incentive to screen the loan to determine the fair loan rate, (ii) the asymmetry of information affects the loan rate charged by the bank ${ }^{9}$, (iii) banks are competing for borrowers ${ }^{10}$, (iv) the credit is merely one part of the overall relationship between the bank and the borrower, and (v) the bargaining power of counterparties and the market structure play a role in the determination of the loan

\footnotetext{
${ }^{9}$ Stiglitz and Weiss (1981) agree on the opaque relation between borrower quality and loan rate. They assume an asymmetric information problem between the borrower and the bank. The form and magnitude of this asymmetry affects the loan rate charged.

${ }^{10}$ This argument is provided by Von Thadden (2004): In order to attract borrowers, low loan rates are offered, leading to expected losses in the short term. Over time, by building up a relationship, information about the borrower is accumulated, creating an information advantage over other lenders. This information allows a relationship bank to extract informational rents from the borrower at a later stage, since the former is able to issue tailored counteroffers for its most valuable customers based on its inside information.
} 
rate as argued in Petersen and Rayan (1995). Rather than explicitly modeling these aspects, I simply assume that the borrower $\mathrm{F}$ pays a fixed loan rate $i$, and, hence, that $i$ is not a signal for the loan quality. ${ }^{11}$

Assuming that screening gives the bank an informational advantage for long maturities, but not for short maturities, deserves some motivation. The intuition is linked to the one provided by Duffee and Zhou (2001). Investments of a borrowing firm and their performance are publicly observable during the life of the loan, but planned investments are not. The credit risk pricing parameters for the short run mainly depend on existing assets as long as the firm does not invest in new projects. The parties are, therefore, likely to agree on these parameters. In contrast, the credit risk pricing parameters for a period far in the future heavily depend on future planned projects. Information about planned projects, however, is difficult to obtain for investors. Due to the close relationship to the borrower ${ }^{12}$, guarantee of confidentiality ${ }^{13}$, offered consulting and expertise, and the borrower's use of various bank services, a bank is in a privileged position to acquire such information through screening.

The idea that the degree of information asymmetry between firms and investors is temporally distributed is well established in the literature (see, e.g., Goswami et al., 1995). Several empirical studies find higher information asymmetry concerning the long term. Aboody et al. (2000) show that despite analysts' search activities and insiders' own trades, R\&D-related private information is not fully revealed prior to the public disclosure of insider trades. Brown and Rozeff (1979) argue that because accounting data has relatively more predictive power for the short-run rather than the long-run performance, firms should exhibit relatively less informational asymmetry regarding the short term.

In light of the results in Gupton et al. (1997), it is reasonable to consider the future recovery rate as the private information. The authors demonstrate that there is a wide

\footnotetext{
${ }^{11}$ Note that I do not incorporate information asymmetry between the borrower and the bank. If the borrower knows his own loan type, screening costs are redundant given that debt contracts exist that reveal the borrower's type to the bank without relying on a costly signal.

${ }^{12} \mathrm{~A}$ formal or informal relationship helps to impose pressure upon the borrower or to perform paretoimproving renegotiations (Gorton and Kahn (2000)). In addition, a relationship can form an implicit contract regarding borrowing and repayment beyond the formal explicit legal contract on which it is based.

${ }^{13}$ Bhattacharya and Chiesa (1995) show how confidentiality of a bank may encourage its clients to reveal more information.
} 
variation in recovery rates even for the same subordination level, which induces that the recovery rate is one of the most uncertain input parameter in a credit risk pricing model. Moreover, Schönbucher (1999a) shows why different perceptions of recovery rates have a relatively high impact on prices of CDSs. Especially for high default probabilities, disparities in recovery rates result in profound differences of CDS spreads. Finally, the borrower's use of bank services may allow the bank to review netting agreements, collateral arrangements, and securities held on behalf of its client, which is important to assess the recovery rate.

To keep the notation as simple as possible, I do not explicitly incorporate the regulatory capital costs on hedged loans. As they are identical for CDS- and CCDS-hedged loans in the Basel framework, they do not influence the contract choice in my model. ${ }^{14}$ In Section 3.6, however, I need to consider the incremental regulatory capital costs imposed by fractional risk retention.

My model incorporates the realistic notion that default can occur any time from $T_{0}$ up to the maturity at $T_{2}$. Artificial restrictions on the timing of the potential occurrence of default would induce contract solutions that are optimal because of the restriction, and not because of the basic problem. ${ }^{15}$ The basic signaling mechanism I explore is robust to introducing counterparty credit risk, random recovery rates, varying recovery payment conventions, the American feature of the call option, or a term structure of interest and loan rates. The reason is that these additional considerations do not eliminate the difference between the value of the call feature of a high and a low loan, on which my approach is based. 


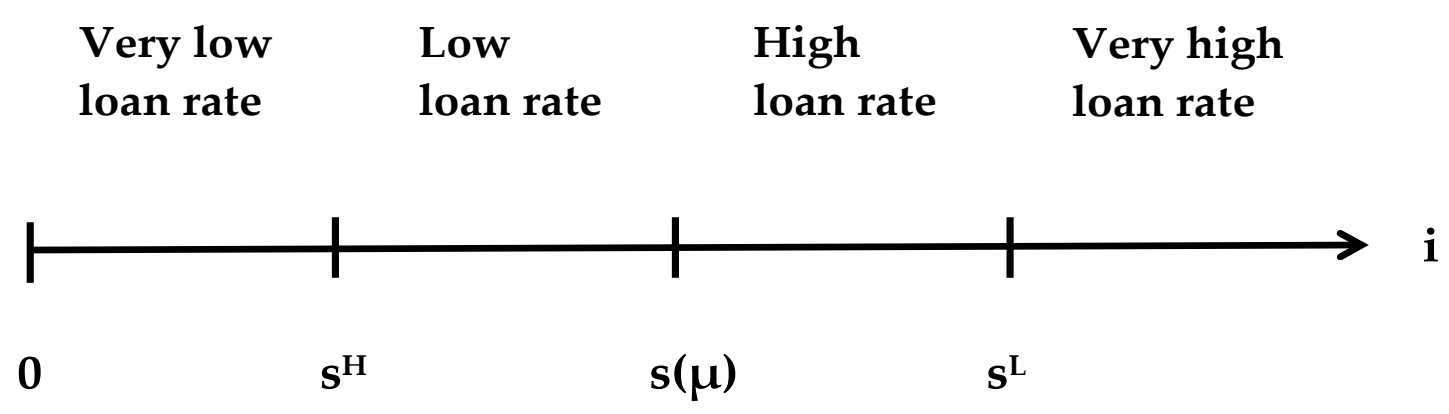

Figure 3: Loan Interest Rates Scenarios. $s^{L}$ denotes the fair CDS rate of a loan with a low recovery rate, $s^{H}$ the one for a loan with a high recovery rate, and $s(\mu)$ is the expected CDS rate based on beliefs $\mu$ about the quality of a loan. The figure shows four possible scenarios for the loan rate $i$ : A very low loan rate is characterized by $i<s^{H}$, a low loan rate by $s^{H} \leq i<s(\mu)$, a high loan rate by $s(\mu) \leq i<s^{L}$, and a very high loan rate by $i \geq s^{L}$.

\section{Analysis}

\subsection{Overview of the results}

The outcome of the analysis of adverse selection depends on the level of the loan rate. Figure 3 characterizes four possible scenarios. In what follows, I illustrate the low loan rate scenario in detail. Table 1 provides an overview of the corresponding results. The results for the remaining scenarios are discussed in Section 3.5.

\subsection{The First Best in an environment of low loan rates}

The analysis in this section assumes a low loan rate, $s^{H} \leq i<s(\mu)$, i.e., the loan rate is higher or equal to the CDS rate of a high recovery loan, but smaller than the expected CDS rate under $\mu$.

The First Best is characterized by a market without information asymmetry among the buyer and the seller of credit risk. A bank is able to assess the recovery rate at default of

\footnotetext{
${ }^{14}$ Loan default losses are completely covered by both CDS and CCDS contracts. In the standardized approach, the call right of the CCDS needs to be at the discretion of the protection buying bank without positive incentives (for example a step-up in cost of cover) to call the protection before maturity (see BIS (2006) page $46 \mathrm{ff}$ ). Both conditions are met by the CCDS structure in my model.

${ }^{15}$ For example, assuming that default can only occur at $T_{2}$ implies that there is no need to hedge from $T_{0}$ to $T_{1}$. At $T_{1}$, however, there is no more information asymmetry, and a simple CDS can be used up to $T_{2}$.
} 


\begin{tabular}{|l|l|l|l|}
\hline & $\begin{array}{l}\text { Condition for } \\
\text { screening }\end{array}$ & $\begin{array}{l}\text { Expected } \\
\text { bank profit }\end{array}$ & $\begin{array}{l}\text { Overall } \\
\text { welfare }\end{array}$ \\
\hline First Best & $\mu\left(i-s^{H}\right) \geq C / V_{0,2}^{f e e}$ & $\mu\left(i-s^{H}\right) V_{0,2}^{f e e}-C$ & $\mu\left(i-s^{H}\right) V_{0,2}^{f e e}-C$ \\
\hline CDS & No screening & 0 & 0 \\
\hline CCDS $(S P>0)$ & $\begin{array}{l}\mu\left(A^{H}-A^{L}\right) \geq \\
C /(1-\mu)\end{array}$ & $\begin{array}{l}\mu\left(i-s^{H}\right) V_{0,2}^{f e e}-C \\
-S P\end{array}$ & as in the First Best \\
\hline CCDS $(S P=0)$ & as in the First Best & as in the First Best & as in the First Best \\
\hline
\end{tabular}

Table 1: $A^{H}$ and $A^{L}$ denote the fair value of the call feature on a high, and a low recovery loan, respectively. C expresses screening costs, $V_{0,2}^{\text {fee }}$ is the present value of receiving one basis point of payments up to $T_{2}$ as long as there is no default, and SP is the signaling premium. The table summarizes the results of credit risk transfer for low loan rates in four cases: (i) without information asymmetry (First Best), (ii) with information asymmetry using a CDS (CDS), (iii) with information asymmetry using a CCDS given a positive signaling premium $(\operatorname{CDD}(S P>0))$, (iv) with information asymmetry using a $\operatorname{CCDS}$ without a signaling premium $(\operatorname{CCDS}(S P=0))$. For each case, the table outlines the condition that induces screening (condition for screening), the expected bank profit given that the condition for screening is satisfied (expected bank profit), and the combined expected profit of the bank and the investor given the condition for screening is satisfied (overall welfare).

a new loan up to maturity. Once this costly information is produced, it becomes common knowledge. Without information asymmetry, a high or low recovery loan can then be hedged against a protection fee corresponding to the fair CDS rate $s^{H}$ or $s^{L}$, respectively.

In what follows the term "Net Present Value of a loan" (NPV) is used:

Definition 3.1. The NPV of granting and hedging a loan from $T_{0}$ to $T_{2}$ is given by $V_{0,2}^{\text {fee }}(i-$ $\left.s^{H}\right)$ for a high recovery loan, and by $V_{0,2}^{f e e}\left(i-s^{L}\right)$ for a low recovery loan. It is positive if the loan rate is higher than the fair CDS rate (good loan), and negative otherwise (bad loan).

A bank exclusively relying on public information always turns down a new loan in the low loan rate scenario, resulting in a market breakdown with zero expected profit. The reason is that $s(\mu)$ is higher than the loan rate, yielding a negative NPV for granted loans. However, a market breakdown induces underinvestment, since good loans are also rejected. Instead of accepting this outcome, it may be worthwhile for a bank to screen $\mathrm{F}$ at costs $\mathrm{C}$. Once B knows whether being faced with a good or bad loan, it grants and hedges the former, and rejects the latter. $\mathrm{B}$ prefers to screen at costs $\mathrm{C}$ if the expected profit of doing so, i.e., $\mu\left(i-s^{H}\right) V_{0,2}^{f e e}-C$, is greater or equal than the zero profit in a market breakdown. Comparing $\mu\left(i-s^{H}\right) V_{0,2}^{f e e}-C$ to zero leads to Proposition 1. 
Proposition 1. For a low loan rate, the bank screens a new loan applicant in the First Best as long as $\mu\left(i-s^{H}\right) \geq C / V_{0,2}^{f e e}$.

Proof. See the Appendix B.

The analysis shows that the ability to screen a loan increases the bank's profit if screening costs are low because a good loan can be detected and granted. The first row of Table 1 shows the condition for screening, the expected bank profit if this condition is satisfied, and the overall welfare. Overall welfare incorporates the total expected profit of the loan and the CDS contract to B and S. ${ }^{16}$ In a competitive market without information asymmetry, the CDS is a zero NPV contract. Hence, the overall welfare from the loan corresponds to the expected bank profit.

\subsection{CDSs as a hedging tool in an environment of low loan rates}

I now introduce information asymmetry between the bank and the investor.

The protection fee in a competitive market for which a risk neutral investor $\mathrm{S}$ with public information is willing to sign a contract hedging the counterparty against the credit risk of a loan is

$$
s(\mu)=\mu s^{H}+(1-\mu) s^{L} .
$$

If $\mathrm{B}$ argues that the underlying loan is of high recovery type, $\mathrm{S}$ may update beliefs to $\rho$, resulting in a protection fee of $s(\rho)=\rho s^{H}+(1-\rho) s^{L} \leq s(\mu)$. A bank will, however, always claim to be hedging a high recovery loan in an attempt to decrease the protection fee, even if it has detected a low recovery loan. There are no costs of doing so. Without a possibility for B to credibly signal the loan's type, costly screening is useless because it does not allow the bank to decrease the protection fee by influencing beliefs. As S anticipates that screening does not take place in an equilibrium, he continues to believe that a loan is of high type with probability $\mu$ and of low type with probability $(1-\mu)$. Given the bank's optimal strategy, $\mathrm{S}$ accepts a contract with a CDS rate equal to $s(\mu)$ to cover the expected credit risk. As a

\footnotetext{
${ }^{16}$ The model in this paper does not account for additional benefits to F out of a granted loan.
} 
consequence, a new loan is not granted because $i<s(\mu)$. The Bayesian equilibrium with CDSs is a market breakdown without screening.

Proposition 2. Information asymmetry between the bank $B$ and the investor $S$ impedes screening activities, if lending constraints are relaxed by transferring the credit risk via CDSs. The loan market breaks down, resulting in underinvestment.

Proof. See the Appendix B.

Conceptually, the result for the low loan rate scenario is in line with Gale (1990) and Hubbard (1998): With asymmetric information, the credit market does not fund all socially efficient projects. The underinvestment problem is evident in Table 1: Recall that in the First Best, a loan is screened as long as the screening-condition is satisfied, yielding a positive overall welfare and expected bank profit. Credit risk transfer exacerbates the situation, resulting in zero profits for all market participants.

The advantage of a CDS-market, i.e., the ability to grant profitable loans even though credit risk constraints are binding, comes along with screening disincentives due to information asymmetry. This friction is costly because an otherwise profitable loan market break down. Banks, therefore, clearly have an incentive to mitigate the investors' informational disadvantage.

\subsection{CCDSs as a hedging tool in an environment of low loan rates}

CDSs provide no signal of loan quality, which causes a market breakdown. This section explains how structuring the hedge in a simple way mitigates information asymmetry to prevent the breakdown.

Let $A^{H}$ denote the fair value of the inherent call feature of a CCDS on a high recovery loan, and $A^{L}$ the one on a low recovery credit. They correspond to the value of a receiver swaption (RS) on the CDS rate of a high, or low loan, respectively, with exercise date $T_{1}$, 
maturity $T_{2}$, and strike $s^{H} \cdot{ }^{17}$ The pricing formula for a RS is given in the Appendix A.5. The following lemma describes the impact of the recovery rate on the value of a receiver swaption:

Lemma 3.2. The value of a receiver swaption is increasing in the recovery rate:

$$
\frac{\partial R S}{\partial R}>0
$$

Proof. See the Appendix B.

Lemma 3.2 allows B to signal the underlying loan's type when hedging the loan through a CCDS by expressing the readiness to pay for the implicit call feature. For an equilibrium, one first needs to ensure that S participates in the credit risk transfer contract. His participation, or individual rationality constraint (IR) requires that

$$
P \geq A(\rho)
$$

in which $\mathrm{P}$ denotes the price paid for the call feature, and $A(\rho)$ is the value of this feature to S under beliefs $\rho$.

Next, I discuss how equilibrium beliefs are formed in case of a CCDS hedge. After screening and detection of a high recovery loan, B is offering a certain call-premium $P$ to $\mathrm{S}$. $\mathrm{P}$ is simply chosen such that (i) a bank that has detected a low recovery loan weakly prefers to stay out of the market, and (ii) a bank weakly prefers to screen and subsequently make an optimal contract choice than to pick the CCDS contract without screening at all. ${ }^{18} \mathrm{~B}$ then selects a CCDS contract if a high loan has been detected, and stays out of the market in case a low loan has been identified. (i) is satisfied if $i V_{0,2}^{f e e}-\left(P+s(\rho) V_{0,2}^{f e e}-A^{L}\right) \leq 0$, while (ii)

\footnotetext{
${ }^{17} \mathrm{~B}$ can buy protection via CDS and synthetically create the possibility to call this contract (replicate a CCDS) by entering a RS. If the RS is exercised at $T_{1}$, then B additionally sells protection up to $T_{2}$. Combined, the CDS and the exercised RS exactly offset each other. A CDS is synthetically called (unwinded) at $T_{1}$ in this way. One is, therefore, able to separate the value of a call feature as the value of a RS.

${ }^{18}$ (ii) is necessary because $\mathrm{S}$ cannot observe the screening-activity itself.
} 
requires that $i V_{0,2}^{f e e}-\left(P+s(\rho) V_{0,2}^{f e e}-\mu A^{H}-(1-\mu) A^{L}\right) \leq \mu\left(i V_{0,2}^{f e e}-\left(P+s(\rho) V_{0,2}^{f e e}-A^{H}\right)-C\right.$. As (ii) is more restricting than (i), the following incentive compatibility constraint (IC), obtained by simplifying (ii), comprises both conditions:

$$
(i-s(\rho)) V_{0,2}^{f e e}+A^{L}+\frac{C}{(1-\mu)} \leq P
$$

To minimize credit risk transfer costs, a bank with a high loan chooses the smallest callpremium $\mathrm{P}^{*}$ that simultaneously satisfies the IR and the IC. If $\mathrm{P}^{*}$ still admits a positive expected profit for $\mathrm{B}, \mathrm{S}$ updates beliefs to $\rho$ as follows: "The underlying loan is of high recovery type with probability one $\left(\rho=1\right.$, and $\left.s(\rho)=s^{H}\right)$, since B would not offer $\mathrm{P}^{*}$ if it had not screened and detected a high recovery loan."

Even if $\mathrm{B}$ is endowed with a mechanism to credibly signal loan quality, it may not be worthwhile to participate in the market. The last step, therefore, is to analyze whether the CCDS approach increases expected bank profits compared to the market breakdown with CDSs:

$$
\mu\left((i-s(\rho)) V_{0,2}^{f e e}-P^{*}+A^{H}\right)-C \geq 0
$$

$(i-s(\rho)) V_{0,2}^{f e e}$ corresponds to today's value of the interest rate minus the protection fee payments up to default or maturity. The left hand side of Inequality (7) shows the expected profit of a bank choosing to screen at costs C. With probability $\mu$, a high recovery loan is detected. $\mathrm{B}$ then signals quality by paying $\mathrm{P}^{*}$ in exchange for a call right value $A^{H}$. With probability $(1-\mu)$, screening reveals a low recovery loan. In this case, B prefers to stay out of the market because misleadingly signaling a high recovery loan by paying $\mathrm{P}^{*}$, or using a CDS would yield a loss (see the IC). The right hand side of Inequality (7) represents the market breakdown that occurs if only CDSs are available. Plugging the lowest $\mathrm{P}^{*}$ satisfying the IR and the IC into Inequality (7) leads to the result in the following proposition:

Proposition 3. The intermediating bank prefers to screen and use CCDSs to the outcome with CDSs, if

$$
\mu\left(A^{H}-A^{L}\right)-\frac{C}{(1-\mu)} \geq 0 .
$$


Whenever $\left(i-s^{H}\right) V_{0,2}^{f e e}+A^{L}+\frac{C}{(1-\mu)} \leq A^{H}$, the Screening Condition (8) reduces to $\mu\left(i-s^{H}\right) \geq$ $C / V_{0,2}^{f e e}$ as in the First Best.

Proof. See the Appendix B.

In contrast to standard credit risk transfer techniques such as CDSs, CCDSs allow B to signal loan quality to S. As a consequence of this possibility to lower the hedging costs for a good loan, B is induced to collect private information on loan quality if $\mathrm{C}$ is not too high. Therefore, underinvestment can be avoided even though the credit risk is fully transferred to S. By screening and the subsequent intermediation of good loans, the bank maintains profitable market activity. This result is not affected by market opacity. The reason is that the price paid for the call feature at contract initiation contains the signaling costs. Even though the bank's subsequent hedging is not publicly observable, the signaling mechanism maintains because the signaling costs are irreversible and can not be avoided by silently hedging on the opaque OTC market.

For a comparison to the First Best, I define the signaling premium (SP) as the difference between the premium $\mathrm{P}^{*}$ and the fair value $A^{H}$ of the call feature. B's expected profit of using a CCDS depends on this signaling premium. The question is how much above $A^{H}$ the premium $P^{*}$ needs to be to induce $\mathrm{S}$ to update beliefs to $\rho$, i.e., to satisfy the IC. In the First Best, B maximizes the trade-off between costs of underinvestment and screening costs. Using CCDSs, it optimizes the trade-off with respect to underinvestment, the signaling premium, and screening costs. If $\left(i-s^{H}\right) V_{0,2}^{f e e}+A^{L}+\frac{C}{(1-\mu)} \leq A^{H}, P^{*}=A^{H}$ is sufficient to update S's beliefs. The signaling premium is equal to zero in this case. Facing exactly the same trade-off, B also realizes the same outcome as in the First Best. Hence, CCDSs allow the bank to reach the First Best under certain conditions, as outlined in Table $1(S P=0)$. The expected bank profit, however, is smaller than in the First Best whenever a certain signaling premium needs to be paid, and a more restrictive condition for profitable screening emerges (see $S P>0$ in Table 1). 


\subsection{Results for very low, high, and very high loan rates}

I first explain the case in which the loan rate is very low, i.e., $i<s^{H}$. As it is publicly known that the loan rate is too low to admit any profitable market activity, no loan is granted or hedged.

Next, consider the very high loan rate case, i.e., $i \geq s^{L}$, in the First Best environment. Before screening, B presumes a high loan being detected with probability $\mu$ and a low loan with probability $(1-\mu)$. Screening before granting and hedging a loan is then expected to yield a bank profit of $V_{0,2}^{f e e}(i-s(\mu))-C$ because both loan types are granted anyway. In contrast, the expected profit increases to $V_{0,2}^{f e e}(i-s(\mu))$ if B lends without screening. A loan is, consequently, granted without screening in the First Best. The same outcome occurs with information asymmetry and CDSs: B has no mean to credibly signal loan quality in a CDS hedge. As a consequence, it omits costly screening. S, anticipating this behavior, assigns beliefs $\mu$ to determine the protection fee on offered loans. B's expected profit, therefore, amounts to $V_{0,2}^{f e e}\left(i-\left(\mu s^{H}+(1-\mu) s^{L}\right)\right)=V_{0,2}^{f e e}(i-s(\mu))$ as in the First Best. In the very high loan rate scenario, each loan has a positive NPV and should be accepted. There is no advantage for $\mathrm{B}$ from spending $\mathrm{C}$ to decide about the acceptance. Creating an instrument to induce screening such as CCDSs, consequently, lacks a benefit. Hence, no screening takes place in the pooling equilibrium, all loan types are approved, and the corresponding credit risk is transferred using CDSs.

Finally, consider the high loan rate case. A bank generates a positive profit by just granting a loan without screening because the loan rate is higher than the expected CDS rate. Cross-subsidization ${ }^{19}$ of bad loans by good loans admits the positive profit. However, screening may still be worthwhile for B if $\mathrm{C}$ is low enough. The reason is that spending $\mathrm{C}$, and thereby learning the true recovery rate, allows the bank to reject bad loans, while good loans can still be granted. In other words, cross-subsidization and overinvestment can be

\footnotetext{
${ }^{19}$ The term "cross-subsidization" describes the following: For low recovery loans the interest rate is too low, and for high recovery loans the interest rate is too high. If the expected profit from granting a loan without screening is positive - and higher than in any screening equilibrium -, the good loans allow the bad ones to be granted without detection. This equilibrium occurs although the bad loans have a negative NPV if it is less profitable to screen and reject bad loans than leaving them in the market.
} 
prevented. Following the proof of Proposition 1, it is easy to show that the bank screens a new loan applicant in the First Best as long as $\left(s^{L}-i\right)(1-\mu) \geq C / V_{0.2}^{f e e}$.

Now, consider the credit risk being transferred via CDS in an environment of high loan rates and information asymmetry. This case illustrates one of the central cause for the 20072008 credit crisis, namely weakened lending discipline that led to a strong credit volume growth (IMF, 2007). Without credit risk transfer, a loan is screened and only a high type is granted if screening costs are low. With access to CDSs, however, a bank's profit is maximized by granting and transferring good and bad loan types to the market without screening. The reason is that $\mathrm{S}$ demands a protection fee $s(\mu)$ for each loan type due to the lack of a credible quality signal. At this credit spread, B just grants any loan without screening. The resulting overinvestment causes information asymmetry costs to the bank given by the difference of the corresponding profit to the one in the First Best, and a loss in overall welfare.

CCDSs address the problem by providing an incentive to screen and reject a low loan. The derivation of the corresponding Proposition 4 is analogous to the one of Proposition 3. The only difference is that Inequality (7) needs to be replaced by

$$
\mu\left((i-s(\rho)) V_{0,2}^{f e e}-P^{*}+A^{H}\right)-C \geq(i-s(\mu)) V_{0,2}^{f e e}
$$

because the bank's profit with CDSs corresponds to $(i-s(\mu)) V_{0.2}^{f e e}$ in case of high loan rates.

Proposition 4. Consider a market characterized by a high loan rate. A pooling equilibrium in which a loan is hedged without screening applies whenever credit risk is transferred via CDSs. The intermediating bank prefers to screen and use CCDSs to the outcome with CDSs, if

$$
\mu\left(A^{H}-A^{L}\right)-\frac{C}{(1-\mu)} \geq(i-s(\mu)) V_{0.2}^{f e e} .
$$

Whenever $\left(i-s^{H}\right) V_{0.2}^{f e e}+A^{L}+\frac{C}{(1-\mu)} \leq A^{H}$, the Screening Condition (10) reduces to $\left(s^{L}-\right.$ $i)(1-\mu) \geq C / V_{0,2}^{f e e}$ as in the First Best.

Proof. See the Appendix B. 


\begin{tabular}{|l|l|l|l|}
\hline & $\begin{array}{l}\text { Condition for } \\
\text { screening }\end{array}$ & $\begin{array}{l}\text { Expected } \\
\text { bank profit }\end{array}$ & $\begin{array}{l}\text { Overall } \\
\text { welfare }\end{array}$ \\
\hline \multirow{2}{*}{ First Best } & $\begin{array}{l}(1-\mu)\left(s^{L}-i\right) \geq \\
C / V_{0,2}^{f e e}\end{array}$ & $\begin{array}{l}\mu\left(i-s^{H}\right) V_{0,2}^{f e e} \\
-\mathrm{C}\end{array}$ & $\begin{array}{l}\mu\left(i-s^{H}\right) V_{0,2}^{f e e} \\
-\mathrm{C}\end{array}$ \\
\hline CDS & No screening & $(i-s(\mu)) V_{0,2}^{f e e}$ & $(i-s(\mu)) V_{0,2}^{f e e}$ \\
\hline \multirow{2}{*}{$\operatorname{CCDS}(S P>0)$} & $\mu\left(A^{H}-A^{L}\right)-(i-s(\mu)) V_{0,2}^{f e e}$ & $\mu\left(i-s^{H}\right) V_{0,2}^{f e e}$ & as in the \\
& $\geq C /(1-\mu)$ & $-C-S P$ & First Best \\
\hline \multirow{2}{*}{$\operatorname{CCDS}(S P=0)$} & as in the & as in the & as in the \\
& First Best & First Best & First Best \\
\hline
\end{tabular}

Table 2: $A^{H}$ and $A^{L}$ denote the fair value of the call feature on a high and a low recovery loan, respectively. C expresses screening costs, $V_{0,2}^{f e e}$ is the present value of receiving one basis point of fee payments up to $T_{2}$ as long as there is no default, and SP is the signaling premium. The table summarizes the results of credit risk transfer for high loan rates in four cases: (i) without information asymmetry (First Best), (ii) with information asymmetry using a CDS (CDS), (iii) with information asymmetry using a CCDS given a positive signaling premium $(\operatorname{CDS}(S P>0))$, (iv) with information asymmetry using a CCDS without a signaling premium $(\operatorname{CCDS}(S P=0))$. For each case, the table outlines the condition that induces screening (condition for screening), the expected bank profit given that the condition for screening is satisfied (expected bank profit), and the combined expected profit of the bank and the investor given the condition for screening is satisfied (overall welfare).

Equation (10) results from a trade-off between the costs of overinvestment, the signaling premium, and screening costs. The outcome is a Second Best solution as shown in Table 2 $(S P>0)$. Whenever $\left(i-s^{H}\right) V_{0,2}^{f e e}+A^{L}+\frac{C}{(1-\mu)} \leq A^{H}$, the signaling premium is equal to zero $(S P=0)$. B then optimizes the trade-off between overinvestment and screening costs, yielding the same results as in the First Best (see Table 2). Again, market opacity does not impede the mechanism.

\subsection{The optimal contract}

This section analyzes whether a CCDS is the optimal security to solve the information asymmetry problem.

A widely discussed alternative signaling mechanism is the partial risk retention approach (see, e.g., Nicolò and Pelizzon, 2008; Duffee and Zhou, 2001). In a partial risk retention contract, a bank retains a fraction $\theta$ of a high loan's credit risk to signal its type. ${ }^{20}$ Besides

\footnotetext{
${ }^{20}$ Many types of risk retention contracts such as maturity mismatches or basket structures can be incorporated in this general framework. Compared to CCDSs that do not need to be called if the bank does not find a replacement hedge at $T_{1}$, a maturity mismatch entails default risk when the CDS expires at $T_{1}$ and the bank can not rehedge.
} 
counterparty risk and the probability of default, capital requirements for credit risk are based on the loss exposure at default in the Basel III jurisdiction (BIS, 2011). Hence, risk retention approaches induce additional regulatory costs compared to CDSs and CCDSs if bank capital is costly. Suppose the regulator requires to hold $\lambda>0$ regulatory capital per unit of default loss exposure retained, and the unitary cost of capital is $\delta>0$. It is assumed that the unitary cost of capital is greater than the cost of deposits that is normalized to zero (see, e.g., Froot and Stein, 1998).

The optimal fraction $\theta^{*}$ to be retained by a bank with a detected high loan is the smallest fraction such that a bank with a low loan or a bank that does not screen do not select to retain this risk exposure. As investors can freely trade fractions of credit risk, the equilibrium credit spread associated with silently trading a retained fraction $\theta^{*}$ on the opaque credit derivative market is given by $s(\mu)$. A bank with a high loan is, consequently, unable to credibly commit ex ante to retain a certain fraction if the costs of silently hedging the residual credit risk resulting from adverse beliefs, $V_{0,2}^{f e e}\left(s(\mu)-s^{H}\right) \theta^{*}$, are lower than the regulatory capital costs of keeping the fractional risk, $\lambda \theta^{*} \delta$, i.e., if

$$
\lambda \delta \geq V_{0,2}^{f e e}\left(s(\mu)-s^{H}\right) .
$$

Hence, partial risk retention contracts do not provide a credible solution to the incentive problem if the regulatory capital requirements $\lambda$ for default loss exposure are large.

The next proposition compares the expected bank profit with a CCDS to the one with a risk retention contract in the low loan rate scenario, assuming that $\lambda \delta$ is lower than in Inequality (11).

Proposition 5. A bank prefers a CCDS to a risk retention contract if

$$
\lambda \delta \geq \frac{\left(\left(i-s^{H}\right) V_{0,2}^{f e e}+C /(1-\mu)+A^{L}-A^{H}\right)\left(s^{L}-s^{H}\right) V_{0,2}^{f e e}}{A^{H}-A^{L}} .
$$

Proof. See the Appendix B. 
Condition (12) shows that CCDSs are optimal for the bank if $A^{H}-A^{L}$ is sufficiently large, or if regulatory costs are high. Additionally, the term on the right hand side is directly linked to the costs of the signal in a CCDS contract, namely to $\left(i-s^{H}\right) V_{0,2}^{f e e}+C /(1-\mu)+A^{L}-A^{H}$. According to Proposition 3, this term is zero if CCDSs admit the First Best outcome. Hence, a bank strictly prefers a CCDS to risk retention whenever the former induces the First Best because $\lambda \delta>0$ by definition. Moreover, a risk retention contract never admits the First Best screening condition due to the regulatory $\operatorname{costs} \lambda$. Finally, the overall welfare with CCDSs corresponds to the First Best whenever the screening condition is satisfied because the signaling premium accrues to the investor. The latter obtains a price for the call that more than compensates for the feature's economic value. In contrast, the signaling costs of a risk retention contract are given by the regulatory capital costs of retaining default loss exposure. As these costs do not accrue to any other market participant, the overall welfare with risk retention is always lower than with CCDSs.

\subsection{Discussion}

Propositions 3 and 4 show that CCDSs permit banks to completely transfer the underlying loan default risk without impeding screening incentives. The screening condition with CCDSs corresponds to the one in the First Best for many parameter combinations.

Screening incentives under complete credit risk transfer are crucial for two reasons. First, insufficient lending discipline and risk retention by banks can seriously undermine the resilience of a banking system (Acharya et al., 2009). CCDSs help to reach the main objective of the Basel III reforms, namely to promote a more resilient banking sector, along both dimensions: They stimulate banks to prudent behavior on the primary loan market without simultaneously entailing default risk retention. Second, a bank usually builds a relationship with the borrower through subsequent lending. According to Tirole (2006), relationship banking is a natural market reaction to the existence of information asymmetries. At some point a bank is, however, reluctant towards more loan grants to the same borrower due to lending constraints arising from, for example, concentration risk. A CCDS permits additional lending to the borrower because the associated default risk can be fully transferred to the 
investor. A risk retention contract would not relax the lending constraint. CCDSs are, therefore, suitable to support relationship building without inducing higher concentration risk or relaxing the incentive to screen.

The Basel III reform is likely to promote the use of CCDSs. The framework clearly tends towards stricter regulatory capital requirements. As shown in Section 3.6, higher regulatory capital costs increase the attractiveness of CCDSs relative to risk retention approaches in terms of bank profit, screening incentives, and overall welfare.

Large information asymmetry also promotes CCDSs. The difference between the high and the low recovery rates can be considered as a measure of information asymmetry. As this difference directly determines the term $\left(A^{H}-A^{L}\right)$ in Inequalities (8), (10), and (12), I conclude that banks particularly favor CCDSs over CDSs and risk retention contracts if the information asymmetry is high. This finding is important as it implies that banks optimally select a CCDS that induces them to screen in those situations in which the information asymmetry problem is large.

A potential concern with the presented mechanism is that because CCDSs consist of two components, i.e., a CDS and a receiver swaption, they could entail larger margin requirements than CDSs. A margin, however, does not affect the bank's contract choice. While the margin increases the costs of using a CCDS, the signaling premium reduces by the same amount. The reason is that a (mimicking) bank that only pretends to be hedging a high loan type with a CCDS also needs to pay the margin, which allows the bank with a detected high loan to reduce the $P^{*}$.

\section{Conclusion}

This paper models a bank that can grant and hedge a risky loan in a market setting with time varying information asymmetry about loan quality. Credit risk transfer via credit default swaps reduces the incentive to screen a loan because the bank can not credibly signal loan quality. I argue that a standardized credit risk transfer contract that fully transfers the loan's default risk can address the problem. In particular, I suggest to use a callable credit default 
swap. With this structure, a bank signals loan quality by expressing its readiness to pay for the implicit call feature. The ability to signal loan quality induces the bank to screen loans ex ante, which reduces information asymmetry costs. I also show that CCDSs represent the optimal contract under the current market developments.

The model can be extended to include interactions between the bank and the borrower. For example, hold-up or collusion among these two players are likely to affect the outcome. It may be in the interests of a hedged bank and the borrower to delay default even though the recovery rate deteriorates, which harms the investor. A model incorporating the strategic game between all players promises further insights into how specialization, intermediation, and relationship banking are affected by the new hedging tools. 


\section{References}

David Aboody, Baruch Lev, Dan Givoly, John Kose, Eli Ofek, and David Ravia. Information asymmetry, r\&d, and insider gains. Journal of Finance, 55:2747-2766, 2000.

Viral Acharya and Alberto Bisin. Counterparty risk externality: Centralized versus over-thecounter markets. Journal of Economic Theory, 149:153-182, 2014.

Viral Acharya, Thomas Philippon, Matthew Richardson, and Nouriel Roubini. The financial crisis of 2007-2008: Causes and remedies. Financial Markets, Institutions and Instruments, 18:89-137, 2009.

George A. Akerlof. The market for "lemons": Quality uncertainty and the market mechanism. Quarterly Journal of Economics, 89:488-500, 1970.

Marc Arnold. The impact of centrally cleared credit risk transfer on banks' lending discipline. Mimeo, 2014.

Adam B. Ashcraft and João A. C. Sanots. Has the CDS market lowered the cost of corporate debt? Journal of Monetary Economics, 56:514-523, 2009.

Ross Barrett and John Ewan. BBA credit derivatives report 2006. Britisch Bankers' Association, 2006.

Antje Berndt and Anurag Gupta. Moral hazard and adverse selection in the originate-todistribute model of bank credit. Journal of Monetary Economics, 56:725-743, 2009.

Sudipto Bhattacharya and Gabriella Chiesa. Proprietary information, financial intermediation, and research incentives. Journal of Financial Intermediation, 4:328-357, 1995.

BIS. International convergence of capital measurement and capital standards: A revised framework-comprehensive version. Bank for International Settlements, 2006.

BIS. Basel iii: A global regulatory framework for more resiliant banks and banking systems. Bank for International Settlements, 2011.

BIS. Triennial central bank survey. Bank for International Settlements, 2013. 
Robert Bliss and Robert Steigerwald. Derivatives clearing and settlement: A comparison of central counterparties and alternative structures. Mimeo, 2006.

Arnoud W. A. Boot, Stuart I. Greenbaum, and Anjan V. Thakor. Reputation and discretion in financial contracting. American Economic Review, 83:1165-1183, 1993.

Lawrence Brown and Michael Rozeff. The predictive value of interim reports for improving forecasts of future quarterly earnings. The Accounting Review, 54:585-591, 1979.

Charles T. Carlstrom and Katherine A. Samolyk. Loan sales as a response to market-based capital constraints. Journal of Banking and Finance, 19:627-646, 1995.

Peter DeMarzo and Darrell Duffie. A liquidity-based model of security design. Econometrica, 67:65-99, 1999.

Douglas W. Diamond. Financial intermediation and delegated monitoring. Review of Economic Studies, 51:393-413, 1984.

Gregory R. Duffee and Chunsheng Zhou. Credit derivatives in banking: Useful tools for managing risks? Journal of Monetary Economics, 48:25-54, 2001.

Darrell Duffie, Ada Li, and Theo Lubke. Policy perspectives on OTC derivatives market infrastructure. Working Paper, 2010.

ECB. Credit default swaps and counterparty risk. 2009.

Günter Franke and Jan P. Krahnen. Default risk sharing between banks and markets: The contribution of collateralized loan obligations. Mimeo, 2005.

Günter Franke, Markus Herrmann, and Thomas Weber. Information asymmetries and securitization design. Mimeo, 2007.

Kenneth A. Froot and Jeremy C. Stein. Risk management, capital budgeting and capital structure policy for financial institution: An integrated approach. Journal of Financial Economics, 47:55-82, 1998. 
Douglas Gale and Martin Hellwig. Incentive-compatible debt contracts: The one-period problem. Review of Economic Studies, 52:647-663, 1985.

William G. Gale. Federal lending and the market for credit. Journal of Public Economics, 42:177-193, 1990.

Gary Gorton and James A. Kahn. The design of bank loan contracts. Review of Financial Studies, 13:331-364, 2000.

Gary Gorton and George Pennacchi. Banks and loan sales: Marketing nonmarketable assets. Journal of Monetary Economics, 35:389-411, 1995.

Gautam Goswami, Thomas Noe, and Michael Rebello. Debt financing under asymmetric information. Journal of Finance, 50:633-659, 1995.

Greg M. Gupton, Christopher C. Finger, and Bhatia Mickey. Creditmetrics, the benchmark for understanding credit risk. Technical Document, J.P. Morgan, 1997.

Glenn H. Hubbard. Capital market imperfections and investment. Journal of Economic Literature, 36:193-225, 1998.

John Hull and Alan White. The valuation of credit default swap options. Mimeo, 2002.

IMF. Global financial stability report. September 2007.

Cho In-Koo and David M. Kreps. Signaling games and stable equilibria. Quarterly Journal of Economics, 102:179-222, 1987.

Robert Innes. Limited liability and incentive contracting with ex-ante action choices. Journal of Economic Theory, 52:45-67, 1990.

Benjamin J. Keys, Tanmoy Mukherjee, Amit Seru, and Vikrant Vig. Did securitization lead to lax screening? Evidence from subprime loans. Quarterly Journal of Economics, 125: 307-362, 2010.

Alan D. Morrison. Credit derivatives, disintermediation and investment decisions. Journal of Business, 78:621-648, 2005. 
Marek Musiela and Marek Rutkowski. Martingale methods in financial modelling. Springer, 2004 .

Antonio Nicolò and Loriana Pelizzon. Credit derivatives, capital requirements and opaque OTC markets. Journal of Financial Intermediation, 17:444-463, 2008.

Dominic O'Kane, Marco Naldi, Sunita Ganapati, Arthur Berd, Claus Pedersen, Lutz Schloegl, and Roy Masal. Guide to exotic credit derivatives. Lehman Brothers, 2003.

J. Osborne, Martin. An introduction to game theory. Oxford University Press, Oxford, 2004.

Mark Pengelly. Hedging spurs growth in credit swaptions. Risk magazine, December, 2010.

Mitchell A. Petersen and Raghuram G. Rayan. The effect of credit market competition on lending relationships. Quarterly Journal of Economics, 110:407-443, 1995.

Amiyatosh Purnanandam. Originate-to-distribute model and the subprime mortgage crisis. The Review of Financial Studies, 24:1881-1915, 2011.

Timothy J. Riddiough. Optimal design and governance of asset-backed securities. Journal of Financial Intermediation, 6:121-152, 1997.

Bernard Salenié. The economics of contracts. MIT Press Cambridge, Massachusetts, 2005.

Philipp J. Schönbucher. A tree implementaion of a credit spread model for credit derivatives. Mimeo, 1999a.

Philipp J. Schönbucher. A libor market model with default risk. Mimeo, 1999b.

Philipp J. Schönbucher. A note on survival measures and the pricing of options on credit default swaps. Mimeo, 2003.

Michael A. Spence. Job market signaling. Quarterly Journal of Economics, 87:355-374, 1973.

Joseph E. Stiglitz and Andrew Weiss. Credit rationing in markets with imperfect information. American Economic Review, 71:393-410, 1981. 
Jean Tirole. The theory of corporate finance. Princeton University Press 41 William Street, Princeton, New Jersey 08540, 2006.

Ernst-Ludwig Von Thadden. Long-term contracts, short-term investment and monitoring. Review of Economic Studies, 62:557-575, 1995.

Ernst-Ludwig Von Thadden. Asymmetric information, bank lending and implicit contracts: The Winner's Curse. Finance Research Letters, 1:11-23, 2004. 


\section{Appendix A Pricing}

In this section, I define the basic valuation concepts for CDSs and options on CDSs. The fundamental references are Schönbucher (1999b), Schönbucher (2003), and Hull and White (2002). The pricing model is set up in a filtered probability space $\left(\Omega,\left(\digamma_{T}\right)_{(T \geq 0)}, \mathbb{P}\right)$. Existence of a spot-martingale measure $\mathbb{Q} \sim \mathbb{P}$ is implied by the absence of arbitrage. The time of the credit event is modeled with a stopping time $\tau$. I assume independence of default events, loan rates, and recovery rates. The riskless interest rate is zero.

\section{Appendix A.1 The forward CDS rate}

A CDS option's underlying is a forward starting credit default swap. A forward starting credit default swap is a CDS starting its life not immediately at $T_{0}$ but at $T_{1}$. If the reference entity defaults before $T_{1}$, the contract is worthless and no payments are made. The payoffs of a forward CDS can be split into a fee leg, paid by the protection buyer, and a protection leg, paid by the protection seller.

\section{Appendix A.2 The fee leg}

The protection buyer pays regular fee payments $s \delta_{n} 1_{T_{n} \leq \tau}$ at predetermined dates $T_{n}$ to the protection seller. $1_{T_{n} \leq \tau}$ is the indicator function that default has not occurred before the payment date $T_{n}$. For tractability, I assume that defaults can only occur on one of the payment dates ${ }^{21}$, and that the daycount fraction is equal to one. $V_{0.2}^{f e e}$ denotes the value at time $T_{0}$ of receiving 1 basis point (bp) of fee payments up to $T_{2}$ :

$$
V_{0,2}^{f e e}=E^{Q}\left[\sum_{n=0}^{N} 1_{T_{n} \leq \tau} \mid \digamma_{T_{0}}\right],
$$

The value of the fee leg is, consequently, $s V_{0,2}^{f e e}$. After a default, no fees are paid, i.e., $V_{\tau, 2}^{f e e}=$ 0 for $\tau \leq T$. The forward starting fee leg is calculated in exactly the same way: I just adapt

\footnotetext{
${ }^{21}$ Default on payment dates is a reasonable assumption given that defaults often become public at times when payments are due.
} 
the summation in Equation (A.1) to include only the forward starting period. The resulting $V_{1,2}^{f e e}$ is multiplied by the forward rate $f_{1,2}$ to arrive at the value of the forward starting fee leg at $T_{0}: f_{1,2} V_{1,2}^{f e e}$.

\section{Appendix A.3 The protection leg}

In case of default during the life of the contract, the protection seller has to pay an amount 1 - $\mathrm{R}$ to the protection buyer. Thus, the corresponding payment is $(1-R) 1_{T_{0} \leq \tau \leq T_{2}}$ at $\tau$. The value of the protection leg at time $T_{0}$ is

$$
V_{0,2}^{\text {prot }}=E^{Q}\left[(1-R) 1_{T_{0} \leq \tau \leq T_{2}} \mid \digamma_{T_{0}}\right]
$$

The value of the forward starting protection leg at $T_{0}$ is $V_{1,2}^{\text {prot }}$, obtained by replacing the indicator function in Equation (A.2) by $1_{T_{1} \leq \tau \leq T_{2}}$ such that only the forward starting period is incorporated.

I now derive the CDS rate. The spot CDS rate simply equals the two legs. The fair forward CDS rate, $f_{1,2}$, at time $T_{0}$ of a forward CDS over the interval $\left[T_{1}, T_{2}\right]$ is the rate at which the forward fee leg has the same value as the forward protection leg, i.e., ${ }^{22}$

$$
f_{1,2}=\frac{V_{1,2}^{\text {prot }}}{V_{1,2}^{\text {fee }}} .
$$

Markt-to-market values of income streams subject to credit risk can be calculated by multiplying with the corresponding fee leg. The value of a fixed spread received from $T_{0}$ to $T_{2}$, for example, is obtained by multiplying this spread by $V_{0,2}^{f e e}$. Suppose a forward CDS over $\left[T_{1}, T_{2}\right]$ has been entered (as protection buyer) before or at $T_{0}$ at a rate $\mathrm{x}$. The markt-to-market value of this position at time $T_{0}$ is $\left(f_{1,2}-x\right) V_{1,2}^{f e e}$. The reason for this result is that one can lock into a fee stream of $\left(f_{1,2}-x\right)$ by selling the forward CDS protection at the current market rate $f_{1,2}$.

\footnotetext{
${ }^{22}$ Note that the fair forward CDS rate is not defined after default.
} 


\section{Appendix A.4 The change of numeraire technique}

Take the example at the end of the previous paragraph. If, instead, one has just the right but not the obligation to enter the forward CDS at time $T_{0}$ at the forward CDS rate $x$, then the value of this right is ${ }^{23}$

$$
\left(f_{1,2}-x\right)^{+} V_{1,2}^{f e e}
$$

Equation (A.4) corresponds to the payoff of an option on a forward-starting CDS with maturity $T_{0}$. Before deriving an option pricing formula, I need to introduce the change of numeraire technique. $^{24}$

For any given spot-martingale-measure $\mathrm{Q}$ and numeraire $A_{T}$, one can define an equivalent pricing measure $Q^{A}$ using the Radon-Nikodym density process: ${ }^{25}$

$$
\left.\frac{d Q^{A}}{d Q}\right|_{T}:=\frac{A_{T}}{b_{T}} \frac{b_{T_{0}}}{A_{T_{0}}}
$$

In our case the bank account is always 1, i.e., $b_{T_{0}}=b_{T}=1$. Prices in the A-numeraire are martingales under the new measure $Q^{A}$.

Unfortunately, a direct application of $V^{f e e}$ as numeraire in a price system is not possible because $V^{f e e}$ can be zero. Thus, a price system in terms of $V^{\text {fee }}$ is undefined after defaults. ${ }^{26}$ Assume $\bar{A}_{T}$ to be the price process of a defaultable asset with zero recovery. For a given $T>T_{0}$, Schönbucher (2003) defines a "promised" payoff $A_{T}^{\prime}$ via $A_{T}^{\prime} 1_{T<\tau}=\bar{A}_{T}$, which permits to define a default-free asset with the price process $E^{Q}\left[\frac{b_{T_{0}} A_{T}^{\prime}}{b_{T}}\right]$. This asset pays $A_{T}^{\prime}$ at $T$ for sure, i.e., the promised payoff is positive. In this case, it can be shown that $Q^{\bar{A}}$ is the measure that is reached when $Q^{A}$ is conditioned on survival until T. ${ }^{27}$ The new probability measure $Q^{\bar{A}}$ attaches zero probability to all events involving a default before T. Schönbucher (2003) circumvents the practical restrictions of this new interpretation by defining the value

\footnotetext{
${ }^{23}$ The reason is that one can now lock into a forward CDS contract at a rate $f_{1,2}$. The protection seller obtains a fixed spread $\left(f_{1,2}-x\right)$ over the future time interval $\left[T_{1}, T_{2}\right]$. It is shown in the last section why one simply needs to multiply a spread over this future period by $V_{1,2}^{f e e}$ to obtain its value.

${ }^{24}$ See Schönbucher (2003).

${ }^{25}$ See, for example, Musiela and Rutkowski (2004).

${ }^{26}$ While the price system itself can break down if the numeraire is zero, the Radon-Nikodym density still remains valid as long as $A_{T_{0}}>0$. It defines a mathematically admissible Radon-Nikodym density.

${ }^{27} Q^{A}$ is the measure for a default-free numeraire defined via the Radon-Nikodym density process.
} 
of $X A_{T}^{\prime}$ at $\mathrm{T}$ in survival:

$$
E^{Q}\left[\frac{b_{T_{0}}}{b_{T}} 1_{\tau>T} X A_{T}^{\prime} \mid \digamma_{t}\right]=\bar{A}_{T_{0}} E^{Q^{\bar{A}}}\left[X \mid \digamma_{T_{0}}\right]
$$

The right hand side of Equality (A.6) is obtained by plugging in the Radon-Nikodym density process with the defaultable asset as numeraire.

\section{Appendix A.5 Option pricing formula}

Armed with the survival-based pricing measure I use the defaultable fee stream for a change of measure to a survival measure. Equation (A.6) is applied to value a receiver swaption on $f_{1,2}$ at $T_{0}$ with maturity $T_{1}$ and strike $x$ :

$$
\begin{aligned}
R S\left(T_{0}\right) & =1_{\tau>T_{0}} E^{Q}\left(\frac{b_{T_{0}}}{b_{T_{1}}}\left(x-f_{1,2}\left(T_{1}\right)\right)^{+} V_{1,2}^{f e e}\left(T_{1}\right) 1_{\tau>T_{1}} \mid \digamma_{T_{0}}\right) \\
& =1_{\tau>T_{0}} V_{1,2}^{f e e} E^{P^{V_{1,2}^{f e e}}}\left(\left(x-f_{1,2}\left(T_{1}\right)\right)^{+} \mid \digamma_{T_{0}}\right)
\end{aligned}
$$

The expectation is taken under the $P^{V_{1,2}^{f e e}}$-measure. $T_{1}$ in parenthesis indicates that $T_{1}$ is the starting date. The key is to understand that $V_{1,2}^{f e e}\left(T_{1}\right) 1_{\left(\tau>T_{1}\right)}$ in Equation (A.7) corresponds to the price process of a defaultable asset with zero recovery at time $T_{1}$. We can, therefore, plug in the corresponding Radon-Nikodym density to generate Equation (A.8). This point is the furthest one can go without making any modeling assumptions apart from the absence of arbitrage. For examples of how to model the distribution of the forward CDS rate $f_{1,2}\left(T_{1}\right)$ under the $P^{V^{f e e}}$-measure, see Schönbucher (2003).

It is important to realize that the underlying credit risk assessment is not necessary to price the option itself. This assessment has already been done when $f_{1,2}$ was formed. 


\section{Appendix B Proofs}

Proof. Proposition 1: $V_{0,2}^{f e e}$ is used to convert risky spread-incomes from $T_{0}$ to $T_{2}$ into present values. A bank selects a strategy by comparing expected profits. When doing so, it anticipates the protection fee for each strategy on the credit derivatives market. The bank's expected profit from screening and subsequent decision about loan granting is $\mu V_{0,2}^{f e e}\left(i-s^{H}\right)-$ $C$. A detected low credit is not approved, since $\mathrm{i}<s^{L}$. Just rejecting a loan without screening the credit quality yields zero expected profit, and granting a loan without screening gives $V_{0,2}^{f e e}(i-s(\mu))<0$. Comparing expected profits and rearranging terms yields the condition in Proposition 1.

Proof. Proposition 2: The Intuitive Criterion of In-Koo and Kreps (1987) can be informally explained as follows: Suppose B makes an out-of-equilibrium offer. B does so based on a certain conjecture about how the investor reacts. The Intuitive Criterion suggests to assign probability one to a B having a high recovery loan, if given the investor's most optimistic conjecture, a high bank finds it optimal to make this offer and to deviate from the equilibrium, while the low bank does not.

Selling a risk on the CDS market permits no credible quality signal. Hence, it is easily checked that the only equilibrium surviving the Intuitive Criterion is a pooling equilibrium without market activity. The bank uses a CDS to hedge the exposure, and S assumes that no screening is taking place. The latter only accepts a protection fee equal or higher than $s(\mu)$, no matter what B claims about the credit's quality. Spending $\mathrm{C}$ in this equilibrium reduces B's expected profit: Screening leads to a NPV of $\operatorname{Max}\left[0, V_{0,2}^{f e e}(i-s(\mu))\right]-C \leq$ $\operatorname{Max}\left[0, V_{0,2}^{f e e}(i-s(\mu))\right]$. The bank is better off if it drops screening and stays out of the market, since spending $\mathrm{C}$ does not allow the bank to reduce the protection fee.

A necessary condition for the existence of a pooling equilibrium without market activity is that B makes negative profits by offering any contract. This condition is satisfied because the loan rate is smaller than $s(\mu)$. Hence, the expected profit is maximized if B stays out of the market. The market breaks down, which causes underinvestment since loans with positive NPVs are also rejected. 
Proof. Lemma 3.2: Changing $\mathrm{R}$ in Equation (A.8) does neither alter $V_{1,2}^{f e e}$ nor $V_{0,2}^{f e e}$. Consequently, the Radon-Nikodym density remains unchanged, and I do not need to take a changing survival-based pricing measure into account. $f_{1,2}\left(T_{1}\right)=\frac{V_{1,2}^{\text {prot }}\left(T_{1}\right)}{V_{1,2}^{f e e}\left(T_{1}\right)}$ can be written as $\frac{(1-R) V_{1,2}^{F p r o t}\left(T_{1}\right)}{V_{1,2}^{f e e}\left(T_{1}\right)}=(1-R) f_{1,2}^{F}$, in which $V^{F p r o t}$ is the value of a claim paying 1 in case of default. Obviously, using Equation (A.8), $R S\left(T_{0}\right)=1_{\tau>T_{0}} V_{1,2}^{f e e} E^{P_{1,2}^{V_{1,2}}}\left(\left(x-f_{1,2}\left(T_{1}\right)\right)^{+}\right.$। $\left.\digamma_{T_{0}}\right)=1_{\tau>T_{0}} V_{1,2}^{f e e} E^{P^{V_{1,2}^{f e e}}}\left(\left(x-(1-R) f_{1,2}^{F}\left(T_{1}\right)\right)^{+} \mid \digamma_{T_{0}}\right)=1_{\tau>T_{0}} V_{1,2}^{f e e} \int_{0}^{x /(1-R)}(x-(1-$ $R) f_{1,2}^{F} \varphi\left(f_{1,2}^{F}\right) \partial f_{1,2}^{F}$, with $\varphi$ expressing the density of $f_{1,2}^{F}$. Now define $\mathrm{F}(\mathrm{Z}, \mathrm{R})=\int_{0}^{Z}(x-(1-$ $R) f_{1,2}^{F} \varphi\left(f_{1,2}^{F}\right) \partial f_{1,2}^{F}$. Then, $\frac{\partial}{\partial R} F\left(\frac{x}{(1-R)}, R\right)=\left.\frac{\partial}{\partial Z} F(Z, R)\right|_{Z=\frac{x}{1-R}}+\frac{\partial}{\partial R} F=\int_{0}^{Z} f_{1,2}^{F} \varphi\left(f_{1,2}^{F}\right) \partial f_{1,2}^{F}$ $>0$, since $\left.\frac{\partial}{\partial Z} F(Z, R)\right|_{Z=\frac{x}{1-R}}=0, f_{1,2}^{F}>0$ and $\varphi\left(f_{1,2}^{F}\right)>0$. As $1_{\tau>T_{0}}$ and $V_{1,2}^{f e e}$ are independent of $\mathrm{R}$, it follows immediately that the RS is increasing in $\mathrm{R}$.

Proof. Proposition 3: Consider a CCDS-contract that is only callable once at $T_{1}$, and that the true recovery rate over the remaining time period to maturity $T_{2}$ is publicly available once this point in time is reached. B tries to maximize expected profits in the set of incentivecompatible, profitable-type-by-type contracts. Assume that B chooses between as many contractual terms as there are possible types of loans. According to Salenié (2005), the revelation principle then implies that one can restrict attention to mechanisms that are both direct (B directly reports his information) and truthful (so that B finds it optimal to announce the true value of his information). In other words, the optimal contract induces B to reveal his type. The purpose of contract choice is to influence beliefs. To maximize the expected profits of the loan and the credit derivative contract by signaling quality, a bank detecting a high recovery loan solves the following program:

$$
\max _{P}\left(i V_{0,2}^{f e e}-\left(P+s(\rho) V_{0,2}^{f e e}-A^{H}\right)-C\right)
$$

s.t.

$$
\begin{gathered}
P \geq A(\rho)(I R) \\
(i-s(\rho)) V_{0,2}^{f e e}+A^{L}+\frac{C}{(1-\mu)} \leq P(I C)
\end{gathered}
$$

This set of equations is justified by the following procedure to obtain a perfect Bayesian 
equilibrium in pure strategies: The bank chooses the swaption premium $P$ by anticipating the resulting protection fee on the credit derivatives market. S signs the credit risk transfer contract, demanding a protection fee dependent on beliefs $\rho$ consistent with the bank's strategy. The contract is set in a way to maintain $\rho=1$.

Equation (B.9) shows the expected profit of a bank with a high recovery loan. Equation (B.10) is the participation constraint (IR) of $\mathrm{S}$ if he assumes that the bank offering a CCDS is indeed of high type with probability $\rho$. S, at least, demands a premium $A(\rho)$ for the call feature. The incentive compatibility constraint (IC) expresses two conditions: A bank with a low recovery credit stays out of the market after screening: $i V_{0,2}^{f e e}-\left(P+s(\rho) V_{0,2}^{f e e}-A^{L}\right) \leq 0$. More restricting, a bank must also weakly prefer to "screen and choose an adequate contract" to just pick the CCDS contract without screening at all: ${ }^{28} i V_{0,2}^{f e e}-\left(P+s(\rho) V_{0,2}^{f e e}-\mu A^{H}-\right.$ $\left.(1-\mu) A^{L}\right) \leq \mu\left(i V_{0,2}^{f e e}-\left(P+s(\rho) V_{0,2}^{f e e}-A^{H}\right)-C\right.$. This condition is necessary because $\mathrm{S}$ cannot observe the screening-activity itself. The lowest premium $P$ satisfying the IC and the IR is labeled $\mathrm{P}^{*}$.

$\mathrm{P}^{*}$ guarantees equilibrium beliefs being such that $\rho=1$ for a CCDS offer if (i) it is profitable to offer $\mathrm{P}^{*}$ after detection of a high credit, (ii) it is profitable to screen. Since $($ ii $) \Rightarrow(i)$, and the alternative outcome is a market breakdown, this condition looks as follows:

$$
\mu\left(i V_{0,2}^{f e e}-\left(P^{*}+s^{H} V_{0,2}^{f e e}-A^{H}\right)\right)-C+(1-\mu) 0 \geq 0 .
$$

$\mathrm{P}^{*}$ induces $s(\rho)=s^{H}$ and $A(\rho)=A^{H}$. The right hand side of Equation (B.12) corresponds to the expected profit in a market breakdown. The left hand side expresses the choice of a CCDS for a high loan, and staying out of the market for a low loan after screening. Public information implies that - before screening - B assumes to be able to offer a CCDS contract with probability $\mu$. If Inequality (B.12) is satisfied for $\mathrm{P}^{*}$, a separating equilibrium with screening holds: A bank with a high loan chooses a CCDS, and staying out of the market is the only rational response after the detection of a low recovery credit. The CCDS (i.e., $\mathrm{P}^{*}$ in the IC) is too expensive for a B with a low loan, and offering a plain vanilla CDS entails

\footnotetext{
${ }^{28}$ The weak monotonic profit assumption permits to skip the IC of a bank with a high recovery loan. See, for example, Tirole (2006).
} 
a bad signal. ${ }^{29}$

Rearranging (B.12) and plugging in $P^{*}$ from the IC yields

$$
\mu\left(A^{H}-A^{L}\right)-\frac{C}{(1-\mu)} \geq 0
$$

The resulting separating equilibrium satisfies the Intuitive Criterion. To check uniqueness, note that a bank with a high recovery loan chooses the minimum swaption premium that still admits to signal the loan type. Consequently, the least-cost separating equilibrium must leave a $\mathrm{B}$ with a low loan just indifferent between the two contracts. It is the most efficient separating perfect Bayesian equilibrium for $\mathrm{B}$, as it entails the lowest signaling premium transferred to S.

Now, consider the following case: If

$$
\left(i-s^{H}\right) V_{0,2}^{f e e}+A^{L}+\frac{C}{(1-\mu)} \leq A^{H},
$$

then the bank with a high recovery loan only needs to pay $A^{H}$ for the call feature to satisfy the IR and the IC. Hence, one concludes that $P^{*}=A^{H}$. Plugging this premium into Equation (B.12) to check the conditions for a screening equilibrium, one obtains $\mu\left(i-s^{H}\right) \geq C / V_{0,2}^{f e e}$. There is no difference to the screening condition in the First Best, and $P^{*}=A^{H}$ also induces the First Best expected profits.

Note that a bank may silently transfer the call feature in period 2 by additionally selling a receiver swaption. It is easily shown why this possibility does not affect the result: Whenever it is optimal for a high bank to sell a RS, it is also optimal to do so for a low bank. As long as $\mu<1$, the high bank is, consequently, faced with unfavorable beliefs and obtains a price below $A^{H}$ if it sells the right to call. Hence, selling a RS would decrease expected profits. As a result, the IC is not tightened by the possibility of silent credit risk transfer.

\footnotetext{
${ }^{29}$ The reason is that by observing the public known parameters, S infers that screening is optimal. Hence, - using the Intuitive Criterion - only a bank with a low recovery loan subsequently tries to offer a CDS. According to (i) and (ii), a bank with a high recovery loan prefers a CCDS. The updated beliefs of S for a CDS-offer are $\rho=0$, yielding a protection fee $s^{L}$ above the loan rate. Naturally, B prefers to stay out of the market than paying this protection fee in a CDS offer.
} 
Suppose next that it is not publicly known whether the bank's credit risk constraint is binding: Speculative banks without lending restrictions may also try to sell receiver swaptions. Assuming most unfavorable beliefs of the investor, i.e., the bank being speculative with probability 1, a high B needs to satisfy the following IC:

$$
(i-s(\rho)) V_{0,2}^{f e e}+A(\mu)+\frac{C}{(1-\mu)} \leq P(I C)
$$

Inequality (B.15) expresses that a low bank silently selling a receiver swaption obtains $A(\mu)$ for this right, as investors assume it is a speculative bank..$^{30}$ The new screening condition is easily derived as

$$
\mu\left(A^{H}-A(\mu)\right)-\frac{C}{(1-\mu)} \geq 0 .
$$

The information about whether the lending constraint is binding is not necessary to maintain a separating equilibrium.

Proof. Proposition 4: The program to maximize takes the following form:

$$
\max _{P}\left(i V_{0,2}^{f e e}-\left(P+s(\rho) V_{0,2}^{f e e}-A^{H}\right)-C\right)
$$

s.t.

$$
\begin{gathered}
P \geq A(\rho) \\
(i-s(\rho)) V_{0,2}^{f e e}+A^{L}+\frac{C}{(1-\mu)} \leq P
\end{gathered}
$$

The first part of the proof corresponds to the one in Proposition 3. The second part is slightly different. Instead of Inequality (7), I need to check if

$$
\mu\left(i V_{0,2}^{f e e}-\left(P^{*}+s^{H} V_{0,2}^{f e e}-A^{H}\right)\right)-C+(1-\mu) 0 \geq i V_{0,2}^{f e e}-\left(\mu s^{H}+(1-\mu) s^{L}\right) V_{0,2}^{f e e},
$$

since the CDS-outcome is a pooling equilibrium with market activity. Just using CDSs is the better choice for B if Inequality (B.20) is not satisfied. Plugging in $P^{*}$ from Equation (B.19)

\footnotetext{
${ }^{30} \mathrm{~A}$ speculative bank without binding lending constraint will not pay the high premium $P^{*}$. However, the possibility of a speculative bank selling a RS has the following effect: A low bank can pretend to be speculative and, hence, sell the RS at a higher price.
} 
yields

$$
\mu\left(A^{H}-A^{L}\right)-\frac{C}{(1-\mu)} \geq(i-s(\mu)) V_{0,2}^{f e e} .
$$

Additionally, one can replace $\mathrm{P}^{*}$ by $A^{H}$ in Equation (B.20) if $\left(i-s^{H}\right) V_{0,2}^{f e e}+A^{L}+\frac{C}{(1-\mu)} \leq A^{H}$. Simplifying gives the same screening condition as in the First Best.

Using the same argument as in the proof of Proposition 3, privacy of credit derivative contracts does not change the results. Additionally, allowing for speculative banks slightly affects the outcome. In the worst case, i.e., if the investor assumes the bank to sell a RS for speculative reasons with probability 1, Condition (B.21) looks as follows:

$$
\mu\left(A^{H}-A(\mu)\right)-\frac{C}{(1-\mu)} \geq(i-s(\mu)) V_{0,2}^{f e e}
$$

Proof. Proposition 5: Consider the risk retention contract. A bank detecting a high recovery loan solves the following program:

$$
\max _{\theta}\left(i V_{0,2}^{f e e}-\theta s^{H} V_{0,2}^{f e e}-(1-\theta) s(\rho) V_{0,2}^{f e e}-C-\delta \lambda \theta\right)
$$

s.t.

$$
\frac{\left(i-s^{H}\right) V_{0,2}^{f e e}+\frac{C}{(1-\mu)}}{\delta \lambda+V_{0,2}^{f e e}\left(s^{L}-s^{H}\right)} \leq \theta
$$

The participation constraint is already incorporated in Equation (B.23), i.e., a competitive credit derivative market requires a fair premium to the investor. Inequality (B.24) expresses the incentive compatibility constraint: A low bank or a bank that does not screen incurs a loss if it retains $\theta$. The high bank will choose the smallest possible fraction $\theta^{*}$ satisfying Inequality (B.24), as retaining risk is costly due to the required regulatory capital.

Finally, the signaling costs of a CCDS must be lower than the signaling costs of a risk retention contract, i.e., $P^{*}-A^{H} \leq \delta \lambda \theta^{*}$, which is expressed in Condition (12). 